\title{
Hydrogen measurement in steel: a query
}

\section{Richard M. Lindstrom}

Received: 16 September 2010/Published online: 23 December 2010 (C) Akadémiai Kiadó, Budapest, Hungary 2010

I found the recent article by Cho and Park (Analysis of hydrogen concentration in low-alloy steel, Journal of Radioanalytical and Nuclear Chemistry 284 (2010), 533-537) most tantalizing. The authors do not give enough details for me to understand how they are able to accurately measure $0.1 \mu \mathrm{g}$ of hydrogen ( $1 \mathrm{ppm}$ in a $100 \mathrm{mg}$ sample) in the presence of a $13 \mu \mathrm{g}$ background, especially since the sample is "irradiated while attached to a paper filter."
They validated their measurements by comparison with ICP-AES, a claim that my colleagues in that field are unable to understand. Although hydrogen can be detected via the $656 \mathrm{~nm}$ line (Spectrochim. Acta 40B (1985), 177-194], since that method in general practice requires the sample to be in water solution, a detailed reference to their procedure is needed. I look forward to reading their future publications. 